\title{
Colorectal cancer screening: tests, strategies, and perspectives
}

\author{
Fabrizio Stracci ${ }^{1,2}{ }^{*}$, Manuel Zorzi $^{3}$ and Grazia Grazzini ${ }^{4}$ \\ ${ }^{1}$ Public Health Section, Department of Experimental Medicine, University of Perugia, Perugia, Italy \\ ${ }^{2}$ Regional Cancer Registry of Umbria, Perugia, Italy \\ ${ }^{3}$ Registro Tumori del Veneto, Padova, Italy \\ ${ }^{4}$ Department of Screening, ISPO Cancer Prevention and Research Institute, Florence, Italy
}

Edited by:

Jimmy Thomas Efird, Brody School of

Medicine, USA

Reviewed by:

Li Tang, St. Jude Children's Research

Hospital, USA

Rao L. Divi, National Institutes of

Health, USA

\section{${ }^{*}$ Correspondence}

Fabrizio Stracci, Public Health

Section, Department of Experimental

Medicine, University of Perugia, via

del Giochetto, Perugia 06125, Italy

e-mail: fabrizio.stracci@unipg.it
Screening has a central role in colorectal cancer (CRC) control. Different screening tests are effective in reducing CRC-specific mortality. Influence on cancer incidence depends on test sensitivity for pre-malignant lesions, ranging from almost no influence for guaiac-based fecal occult blood testing (gFOBT) to an estimated reduction of $66-90 \%$ for colonoscopy. Screening tests detect lesions indirectly in the stool [gFOBT, fecal immunochemical testing (FIT), and fecal DNA] or directly by colonic inspection [flexible sigmoidoscopy, colonoscopy, CT colonography (CTC), and capsule endoscopy]. CRC screening is cost-effective compared to no screening but no screening strategy is clearly better than the others. Stool tests are the most widely used in worldwide screening interventions. FIT will soon replace gFOBT. The use of colonoscopy as a screening test is increasing and this strategy has superseded all alternatives in the US and Germany. Despite its undisputed importance, CRC screening is under-used and participation rarely reaches $70 \%$ of target population. Strategies to increase participation include ensuring recommendation by physicians, introducing organized screening and developing new, more acceptable tests. Available evidence for DNA fecal testing, CTC, and capsule endoscopy is reviewed.

Keywords: colorectal cancer, advanced adenoma, screening, flexible sigmoidoscopy, total colonoscopy, fecal tests, CT colonography, capsule endoscopy

\section{ROLE OF SECONDARY PREVENTION IN COLORECTAL CANCER CONTROL}

Screening has a central role in colorectal cancer (CRC) control. Even if incidence studies show that the majority of large bowel cancers are sporadic, few protective and risk factors for the disease have been consistently identified so far (e.g., alcohol, red and processed meat intake, obesity, smoking, physical activity, and aspirin use) (1). Modifiable factors are associated with slightly elevated risks of developing CRC, in most cases between 1.2 and 2.0. Some established risk factors are widely diffused in the general population so that they are responsible for a substantial share of disease burden and, thus, are potential targets for preventive interventions (2). However, changing dietary habits and physical activity levels is difficult. Typically, the Western lifestyle is associated with an unfavorable pattern of risk factors and with high CRC incidence rates $(3,4)$ and these, together with mortality trends, are also reported in developing countries $(5,6)$. CRC prognosis has slowly been improving (7). Progress has been made in the treatment of the disease, particularly for rectal cancer (8). However, both advanced age and stage at diagnosis limit the opportunity for curative treatment in many cases (9). Diagnosis at earlier stages in disease development has led to a dramatic change in prognosis and to more conservative treatment (10). Thus, screening is presently the key intervention for CRC control.

\section{DISEASE IS SUITABLE FOR SCREENING}

Colorectal cancer is an ideal target for screening interventions (11).
Colorectal cancer is an important health burden. With 746,000 cases in males (10.0\% of total cancer cases) and 614,000 cases in women (9.2\% of total), large bowel cancer is estimated to be the third (following lung and breast cancer) most frequent cancer worldwide in both sexes combined (12). In western countries, CRC is the most frequent cancer in both sexes (13). CRC is also a leading cause of cancer death, ranking fourth after lung, liver, and stomach cancer (12).

In the majority of cases, the disease develops over many years through the so-called adenoma-carcinoma sequence (14). Detection and removal of pre-malignant lesions can prevent progression to cancer and decrease incidence (15-18). CRC, as with many other cancers, is curable in most cases if detected at an early stage (10).

\section{COLORECTAL CANCER SCREENING TESTS}

Screening tests are available to detect pre-malignant lesions and cancer at early stages. Screening tests are classified in two groups: (i) indirect tests looking for the presence of markers of colorectal neoplasm in the stool; (ii) tests based on direct visualization of neoplasm in the large bowel. Currently, both stool-based [i.e., fecal occult blood test (FOBT) and fecal immunochemical test (FIT)] and endoscopy-based tests [i.e., flexible sigmoidoscopy (FS) and total colonoscopy (TC)] are almost exclusively used in ongoing opportunistic and organized CRC screening worldwide.

There is evidence from randomized controlled trials (RCT) and meta-analyses that guaiac-based [guaiac-based fecal occult blood testing (gFOBT)] and FS screening decrease CRC-specific 
mortality $(15,19)$. FIT shares the same indirect target for the presence of colorectal neoplasm with gFOBT; that is, the presence of blood in the stool. There is sufficient evidence that FIT outperforms gFOBT in terms of sensitivity $(20,21)$ and compliance with invitation (22). There is no available evidence from RCTs supporting the efficacy of colonoscopy as a CRC screening test and results from the ongoing RCTs will take decades to appear (23-25). However, TC is considered an effective screening test for CRC based on the following arguments: (i) evidence available for FS applies to TC as well since both tests are based on direct visualization of intestinal lumen; (ii) mortality reduction achieved with FOBT tests depends on colonoscopy as the confirmatory test; and (iii) available observational studies confirm that TC is highly effective in reducing CRC mortality and incidence (26). CRC screening is also cost-effective if compared to no screening $(27,28)$. Screening tests currently in use have recently been reviewed in detail $(15,21,29)$.

\section{GUAIAC-BASED FECAL OCCULT BLOOD TEST}

Four large RCTs (30-33) showed that a screening program based on a gFOBT repeated every 1 or 2 years reduces CRC-specific mortality by $16 \%$ (up to $23 \%$ according to the per-protocol analysis) (34).

Some characteristics of gFOBT may limit compliance: they must be collected from three consecutive stools and they are sensitive to diet intake of hemoglobin (35). This led to the indication of dietetic restrictions at the price of loss in compliance; diet indications were subsequently dropped because of limited clinical significance (36-39). gFOBT is also sensitive to bleeding of the upper gastro intestinal (GI) tract (40). A further limitation of gFOBT is its low sensitivity for CRC (25-38\%) and for advanced adenomas (AA) (16-31\%) (20), the latter probably being the reason for the lack of incidence reduction among screened populations (34). Test sensitivity may be increased by rehydrating the test windows before development (41), but this significantly affects specificity $(39,42)$. Since the reading of the test is not automated, an inter-operator as well as a batch-to-batch variability has been reported (39). gFOBT is more stable than FIT if exposed to high temperature (43).

\section{FECAL IMMUNOCHEMICAL TEST}

No RTC on the impact of FIT-based screening on CRC mortality has been carried out. A recent ecological study showed a $22 \%$ reduction in CRC-specific mortality in areas where FIT screening programs were active compared to controls (44). The impact of screening with FIT on incidence rates has also been reported (18). Further evidence of FIT test efficacy is indirect, based on a large number of trials comparing performance of different FIT tests with gFOBT (45-54). These studies are difficult to compare because they used different positivity cut-offs and different sample numbers $(51-53,55)$. Overall sensitivity of FIT is higher than gFOBT both for CRC (61-91\%) and for AA (27-67\%) and the test has a comparable specificity (ranging from 91 to $98 \%$ versus 98-99\%) (40).

Fecal immunochemical tests are specific for human blood and insensitive to upper GI bleeding (21). There are qualitative FIT tests that produce a binary result (positive or negative), whose positivity cut-off may not be adjusted and whose reading is not automated. Their performance showed a large variability among manufacturers (56). Quantitative FIT produce a quantitative result of the fecal hemoglobin concentration, generally as nanograms of hemoglobin per milliliter buffer added and whose positivity cut-off may be adjusted.

The best number of samples and the positivity cut-off have not yet been defined and this uncertainty reflects on recommendations published in different countries (45, 50, 57-60). However, complicated stool handling may negatively affect screening compliance; according to two studies, 60-62\% with 1-sample FIT versus $47-50 \%$ with three-samples gFBOT $(50,52)$. In addition, recent findings show that increasing the number of FIT samples does not affect the main performance indicators of FITs for CRC (61). It is thus reasonable to use a single sampling and to act on the cut-off to adjust the desired sensitivity $(22,62)$. Some trials have identified a protocol based on a single sample with a positivity cut-off of $75 \mathrm{ng} / \mathrm{ml}$ as a good trade-off between sensitivity and specificity $(49,63-65)$. Storage conditions (e.g., excessive temperature) may increase false-negative rates (64) and require technology solutions by the manufacturers. According to some recent studies, FIT is the most cost-effective tool for CRC screening (66-68) with a sensitivity (76\%) and a specificity (95\%) comparable to TC (24).

The European Guidelines recommend FIT for programs adopting a strategy based on fecal occult blood test (21).

\section{FLEXIBLE SIGMOIDOSCOPY}

Randomized controlled trials showed that screening with FS reduces CRC mortality by $22-31 \%$ and incidence by $18-23 \%$ through visual inspection of colic mucosa, biopsy taking and polyp removal in the distal tract of colon (69-71). A populationbased trial showed similar results after a median follow up of 10.9 years $(72)$.

The impact of screening with FS on incidence and mortality rates is limited to the distal colon, while RCTs showed no significant differences as regards the distal tract. A combined strategy using FS and gFOBT/FIT did not seem to solve the problem $(72,73)$ while it would increase endoscopic workload and reduce participation $(72,74,75)$.

Overall, FS is a safe test: very low complication rates (mainly perforations and bleeding requiring transfusion) have been reported (76).

\section{TOTAL COLONOSCOPY}

Total colonoscopy allows direct visualization of the colonic mucosa, biopsy of lesions, and polyp removal over the whole colon. Sensitivity and specificity for CRC and AA are very high, even if a miss-rate of CRC of between 0.2 and $5.0 \%$ was reported (77-82). TC is the confirmatory test used in case of a positive test for all the above screening strategies $(21,42,83)$.

Evidence of efficacy derives from observational studies, showing a relevant impact on incidence (reduced by 66-90\% compared to the general population) and mortality (31-65\%) (16, 84-87).

Total colonoscopy as a CRC screening test is not free from limits. A high inter-operator variability in the adenoma detection rate has been reported and this feature has been associated with the subsequent risk of CRC (88). Moreover, retrospective analyses questioned the capability of reducing incidence and mortality 
from proximal CRC in community settings $(89,90)$. Thus, proper training programs for endoscopists are necessary, as well as continuous quality assurance (91). Collateral effects of TC are rare but more frequent than with FS (20).

Many characteristics negatively affect the acceptability of TC as a first-line screening test: it is an invasive examination, which requires an even more invasive bowel cleansing and it is timeconsuming, expensive, and painful. Even if in the US the uptake of TC is increasing (92), in the EU countries compliance has been very low (93).

\section{GEOGRAPHIC DISTRIBUTION OF CRC SCREENING}

Diffusion of CRC screening shows a marked geographic variation (94). Screening is more frequently available in high incidence, high resources western countries. CRC screening practices in Europe have recently been reviewed by Altobelli et al. (13). Stool-based tests are more used than endoscopy. gFOBT is the recommended test in many countries like UK, France, and Finland. FIT is the test of choice in Spain, the Netherlands, and in most Italian programs. Screening is mainly national and programed in European countries and includes the 50-74 age group as the target population. Opportunistic screening is diffused in Austria and Germany, and, outside Europe, in Japan, Australia, and Canada (95). Germany, Poland, and the US adopt TC as CRC screening test, alone or as an alternative to other possible test choices. The US has a longstanding history of CRC screening dating back to the 80s. CRC screening in the US is not diffused in the form of organized programs but different test choices are equally recommended [i.e., (1) annual high-sensitivity gFOBT or FIT, following the manufacturer's recommendations for specimen collection; (2) FS every 5 years; (3) TC every 10 years; (4) double-contrast barium enema every 5 years; or (5) CT colonography (CTC) every 5 years] (96). However, TC has progressively become the most widely used test in the US and is increasingly considered the gold standard test for CRC screening because of the claimed effectiveness in detecting cancer and advanced pre-malignant lesions in comparison with stool-based tests that primarily detect cancer at early stages (9799). The preference of TC as a CRC screening test in the US is largely attributable to the classification of stool-based tests as aimed primarily at detecting cancer and as a test based on structural examination of large bowel as aimed at detecting both cancer and advanced pre-malignant lesions (96).

\section{SCREENING STRATEGIES}

Studies agree that at present there is no clear evidence of the superiority of one screening test and strategy over the others $(28,99)$.

High variability of screening interventions worldwide reflects this situation. Determinants of the adoption of screening strategies include: (i) test performance and, in particular, ability to detect pre-malignant lesions and decrease incidence of invasive cancer; (ii) acceptability of tests and screening participation; and (iii) resource needs associated with different strategies.

Fecal immunochemical test is increasingly considered a better test than gFOBT because of better accuracy, compliance, and costeffectiveness (100). Moreover, FIT showed better sensitivity than gFOBT for advanced neoplasia and this feature should also result in a larger decrease of CRC incidence $(18,19,101)$.
Among tests based on large bowel structural examination, TC is the preferred test, despite high costs and invasiveness. In particular, in the US, TC has progressively gained the widest diffusion over the other available tests, including FS (97). Endoscopy tests showed better sensitivity than FIT for the diagnosis of premalignant polyps and, particularly, advanced neoplasia. Thus, endoscopy tests are likely to confer better individual protection and have a stronger influence on cancer incidence if compared to FIT $(17,102)$. However, FIT is a better accepted screening test than FS and TC. Thus higher participation in screening using FIT may, to some extent, balance lower sensitivity than endoscopy tests (103-105).

Recent studies comparing FIT to endoscopy tests in a single screening round confirmed that FIT is associated with the highest participation $(23,101)$. Higher participation rates achieved by FIT reduce, but do not eliminate the gap in detection rate of cancer and AA compared to endoscopy tests. However, screening strategies using FIT have typically shorter intervals between subsequent test repetition that should further reduce or even reverse the difference in detection rates with respect to FS and TC (101). Results of studies comparing endoscopy tests with repeated rounds using FIT will depend on both test sensitivity and compliance with subsequent invitation in the FIT group $(106,107)$.

The diagnosis of pre-malignant lesions and consequent decrease of incident cancers is a much desirable feature of CRC screening. The concept of over-diagnosis apparently does not apply to CRC screening since a steeply increasing incidence does not follow screening introduction and, on the contrary, a decreasing incidence trend is reported in the US, after decades of CRC screening progressive diffusion (97). However, the concept of over-diagnosis in CRC should also be tested against incidence of pre-malignant lesions. In particular, the rate of colectomies should be monitored and compared among different screening tests and to non-screened groups or populations.

In conclusion, FIT testing is increasingly the most used CRC screening strategy. In a few countries, including US and Germany, TC is recommended and is the most used test. Cost and availability of endoscopy resources may be the limiting factors in the adoption of TC screening strategy.

\section{IMPROVING OUTCOMES IN CRC SCREENING}

Improvement of CRC screening is a much desirable aim that is actively pursued through research to improve performance of tests and strategies to increase screening participation.

Despite its central role in CRC control and the availability of a range of effective tests, CRC screening is typically under-used. In the US participation in CRC screening has been increasing since its introduction in the 80s but was still below 70\% in 2010 (97). In European countries, screening started much more recently than in the US and participation rates are generally lower than in US (13).

Strategies to improve participation in screening interventions were reviewed by Jepson et al. (108) and, more recently, by Camilloni et al. (109). The implementation of organized interventions may improve participation and reduce inequalities in screening uptake if compared to opportunistic screening (11). This strategy has been adopted in many European countries and is actively considered in Germany and US $(13,110,111)$. 
Physician recommendation influences participation (112). Sequential offering of available screening tests may contribute to maximize participation $(113,114)$. Research on screening tests with improved features including better acceptability is ongoing and serum markers represent a possible example of acceptable screening tests (115).

Better diagnostic performance is another way to improve CRC screening outcomes. Performance could be improved through: (i) strategies based on the combination of existing tests or (ii) improvement of screening tests that can be achieved with: (1) improvement of existing tests, (2) introduction of new diagnostic tests. CRC screening strategies currently in use consist either in opportunistic screening allowing individual selection of a test among many recommended alternatives or in organized screening based on the administration of a single type of test. The combination of tests with different features may be investigated to improve performance. Combination of FIT and FS has been discussed above. A simulation model showed that FIT at younger age combined with colonoscopy at older ages may represent a cost-effective alternative to single test strategies (116).

Research is continuously being done to improve existing tests or develop new ones. FIT can be considered an improvement of the older stool-based test gFOBT (100). As an example of innovation of existing tests, full-spectrum TC has recently been shown to have higher sensitivity for colorectal adenomas than traditional TC (117). Many new tests are currently in development. We briefly review tests that have been used or are ready for field use.

\section{FECAL DNA TESTING}

Fecal sample testing using molecular diagnostic tests is emerging as a potentially important new approach. There is a strong biologic rationale to pursue this technology, given that adenoma and cancer cells that contain altered DNA are continuously shed into the large bowel lumen. DNA is stable in the feces and it can therefore be extracted for analysis. Due to the heterogeneity of cancer, no single molecular marker has shown an optimal sensitivity, while panels of different markers in early studies have allowed a higher detection rate for both CCR and AA.

However, observations on larger size population studies appeared less encouraging, showing only fair sensitivity for the detection of CRC and low sensitivity for the detection of AA (118, 119). Significant technical improvements have been carried out in recent years, which have raised sensitivity of these tests for the detection of colonic lesions.

A very recent study by Imperiale (120) compared a multitarget stool DNA test with a commercial FIT among a large series of subjects at average-risk for CRC. The sensitivity of the DNA test for the detection of both CRC (92.3\%) and advanced precancerous lesions (42.4\%) was very impressive, being superior to that of FIT by a difference of about $20 \%$ points, even if FIT was more specific for CRC and advanced precancerous lesions (120). A higher rate of non-adequate samples respect to FIT (6.3 versus $0.3 \%$ ) was also registered. DNA fecal testing is an addition to the stool-based tests for CRC screening but further studies are needed to understand whether stool DNA testing has any role in CRC organized screening, taking into account other key factors yet to be assessed, such as the screening interval, adherence, and costs.

Clinical proteomics is an emerging issue in cancer research. Potentially, blood proteomics tests in the near future will be able to detect patterns of proteins associated with cancer or low molecular-weight compounds related to an abnormal cell growth. In the words of Liotta and Petricoin (121) "the lowmolecular-weight region of the blood proteome is a treasure trove of diagnostic information ready to be harvested by nanotechnology." Unfortunately, no clinical applications are available at the moment and large multicenter studies in average-risk populations are needed in order to fully understand the true potential of this new biomolecular technology.

\section{CT COLONOGRAPHY}

CT colonography, or virtual colonoscopy, is a poorly invasive radiological technique for imaging the large bowel. It provides two-dimensional and three-dimensional images. A bowel insufflation with carbon dioxide is needed. If polyps or CRC are detected on CTC, patients are referred to TC. CTC is well tolerated by patients $(122,123)$ and it can be performed even with limited bowel preparation. Several studies have demonstrated that CTC has a high-sensitivity for the detection of colonic lesions that was equal to $83-93 \%$ for polyps larger than $10 \mathrm{~mm}$ and to $60-86 \%$ for intermediate polyps with a $6-9 \mathrm{~mm}$ in size (124-129). Specificity of CTC resulted also very high for lesions >9 mm (95-97\%) (125, 126, 128).

The risk of complications is extremely low, with no perforations or other serious complications in a large CTC screening cohort (130).

CT colonography reading may be time-consuming for the radiologist and this aspect is particularly interesting in a screening setting. Systems for helping radiologists in detecting colonic lesions at CTC have been developed [Computer aided diagnosis (CAD)]. Few data (131) suggest that this strategy has a sensitivity for polyps similar to that with unassisted reading and allows for a reduction in the reading time (132).

For these features, CTC could be a good alternative as primary test in a screening setting.

A RCT conducted in the Netherlands (133) compared participation in a CRC screening setting with CTC or with TC, showing that adherence of invited subjects was significantly better with CTC than with TC. On the other hand, TC identified significantly more advanced neoplasia per 100 participants than did CTC, even if the diagnostic yield for advanced neoplasia per 100 invitees was similar for both strategies.

In the perspective of including CTC as a screening test, some considerations about potential disadvantages are needed:

- CTC-based screening may produce a high referral rate to colonoscopy, with an increase of costs.

- Detection of extracolonic lesions: CTC displays the abdominal organs, thus the prevalence of extracolonic diseases that require further investigation may be substantial (6\% in asymptomatic average-risk populations). Risks and costs associated with false-positive results and unnecessary diagnosis should be considered (134). 
- Exposure of individuals to ionizing radiation; the probability of radiation-induced malignancy is very low, especially with low dose protocols.

Two randomized clinical trials are underway in Italy comparing CTC as primary test versus biennial FIT and versus TC (135) or versus FS (136). Both these trials will provide reliable information concerning participation/acceptability, diagnostic yield, and costs of screening with CTC in comparison with FIT or FS. The trials will also evaluate the role of CAD in a screening setting.

Pending the results of these studies, we currently have no available data about the effectiveness of CTC as primary test in CRC screening.

However, organized screening programs have already introduced CTC as a current complementary assessment for FIT positive patients with incomplete colonoscopy or with contraindications to colonoscopy (137).

The potential role of CTC as a first-line CRC screening strategy is very attractive. In this setting, CTC may offer clear advantages, such as accuracy, safety, and subject acceptance. Future research will tell us whether this strategy might be a good option in terms of participation, costs, and benefit/risks ratio for the CRC screening programs.

\section{COLON CAPSULE ENDOSCOPY}

Colon capsule endoscopy, also called video or wireless capsule endoscopy, is a relatively new technique to visualize the colon, developed by Given Imaging Ltd. for small bowel imaging. In 2006, a first generation of capsule, dedicated to colon investigation [PillCam Colon capsule endoscopy (CCE)] was developed. Images are transmitted to a computer workstation for the visualization. In case of abnormalities detected by CCE, a colonoscopy is needed to allow removal of polyps and subsequent pathologic diagnosis. Patients have to undergo bowel cleansing before the CCE. Bowel preparation is specifically designed not only to clean the colon, but also to allow colonic distension and propel the capsule through the colon. Even small amounts of residual stool may influence visualization of the colonic mucosa (138).

One study evaluated the diagnostic accuracy of CCE in a prospective setting with high-risk patients (139). Sensitivity and specificity for detecting polyps $\geq 6 \mathrm{~mm}$ was 64 and $84 \%$, respectively, whereas sensitivity and specificity for advanced adenoma detection was 73 and 79\%, respectively. Recently, a secondgeneration colon capsule (CCE-2) has been made available. The new CCE measures $11.6 \mathrm{~mm} \times 31.5 \mathrm{~mm}$, with a widened angle of view, thus allowing for nearly $360^{\circ}$ coverage of the colon. The device can adapt the image acquisition rate depending on the speed of progression of the capsule along the colon. To further save battery energy, CCE-2 can "choose" to work at a low rate of 14 images per minute until small bowel images are detected.

CCE-2 is provided with a new data recorder (DR3) endowed with an artificial intelligence software. DR3 can communicate with the capsule that listens to the "thinking" Data Recorder 3 and carries out the orders received by it. Moreover, the DR3 guides the medical staff and the patient through the procedure, buzzing, and displaying instructions on its liquid crystal screen.
Two studies conducted in Israel (140) and in Italy (141) have evaluated CCE-2 diagnostic accuracy for polyps. In the first one, CCE- 2 was prospectively compared with conventional colonoscopy as the gold standard in a cohort of 98 patients with known or suspected colonic disease. Per-patient CCE-2 sensitivity for polyps at least $6 \mathrm{~mm}$ in size was $89 \%$, and at least $10 \mathrm{~mm}$ in size was $88 \%$, with specificities of 76 and $89 \%$, respectively. In the European trial, 109 patients were considered for analysis. Perpatient CCE-2 sensitivity for polyps at least $6 \mathrm{~mm}$ in size was $84 \%$ (95\% CI 74-95\%), and at least $10 \mathrm{~mm}$ in size was $88 \%$ (95\% CI 76$99 \%$ ) with a specificity of 64 and $95 \%$, respectively. Data regarding diagnostic accuracy of the CCE- 2 are encouraging, but evidence concerning the diagnostic performance of this new technology is in any case limited and based only on a few studies with a small number of subjects recruited. Moreover, studies in an average-risk screening population are still lacking. For this reason, a multicenter prospective study is underway in Italy with the aim of assessing the accuracy of PillCam colon 2 in a screening setting.

Colonic preparation for a colon capsule represents another challenge. Recent studies evaluated a new protocol with a splitdose PEG and a low dose of NaP, reporting good results (142).

In conclusion, the possible role of CCE as the primary test in CRC screening represents a fascinating perspective, but further studies are needed to understand the real impact of this new technique in the non-invasive diagnosis of CCR and its precursors.

\section{ACKNOWLEDGMENTS}

We would like to thank Mrs. Catherine Brandt for English review.

\section{REFERENCES}

1. Brenner H, Kloor M, Pox CP. Colorectal cancer. Lancet (2014) 383:1490-502. doi:10.1016/S0140-6736(13)61649-9

2. Rose G. The Strategy of Preventive Medicine. Oxford: Oxford University Press (1992).

3. Chan AT, Giovannucci EL. Primary prevention of colorectal cancer. Gastroenterology (2010) 138:2029-43. doi:10.1053/j.gastro.2010.01.057

4. Bray F, Jemal A, Grey N, Ferlay J, Forman D. Global cancer transitions according to the human development index (2008-2030): a population-based study. Lancet Oncol (2012) 13:790-801. doi:10.1016/S1470-2045(12)70211-5

5. Chatenoud L, Bertuccio P, Bosetti C, Malvezzi M, Levi F, Negri E, et al. Trends in mortality from major cancers in the americas: 1980-2010. Ann Oncol (2014) 25:1843-53. doi:10.1093/annonc/mdu206

6. Arnold M, Karim-Kos HE, Coebergh JW, Byrnes G, Antilla A, Ferlay J, et al. Recent trends in incidence of five common cancers in 26 European countries since 1988: analysis of the European cancer observatory. Eur J Cancer (2013). doi:10.1016/j.ejca.2013.09.002

7. Rutter CM, Johnson EA, Feuer EJ, Knudsen AB, Kuntz KM, Schrag D. Secular trends in colon and rectal cancer relative survival. J Natl Cancer Inst (2013) 105:1806-13. doi:10.1093/jnci/djt299

8. Renouf DJ, Woods R, Speers C, Hay J, Phang PT, Fitzgerald C, et al. Improvements in 5-year outcomes of stage II/III rectal cancer relative to colon cancer. Am J Clin Oncol (2013) 36:558-64. doi:10.1097/COC.0b013e318256f5dc

9. Haggar FA, Boushey RP. Colorectal cancer epidemiology: incidence, mortality, survival, and risk factors. Clin Colon Rectal Surg (2009) 22:191-7. doi: 10.1055/s-0029-1242458

10. DeSantis CE, Lin CC, Mariotto AB, Siegel RL, Stein KD, Kramer JL, et al. Cancer treatment and survivorship statistics, 2014. CA Cancer J Clin (2014) 64:252-71. doi: $10.3322 /$ caac. 21235

11. Levin TR, Jamieson L, Burley DA, Reyes J, Oehrli M, Caldwell C. Organized colorectal cancer screening in integrated health care systems. Epidemiol Rev (2011) 33:101-10. doi:10.1093/epirev/mxr007

12. Ferlay J, Soerjomataram I, Ervik M, Dikshit R, Eser S, Mathers C, et al. GLOBOCAN 2012 v1.0, Cancer Incidence and Mortality Worldwide: IARC Cancer Base 
No. 11. Lyon: International Agency for Research on Cancer (2013). Available from: http://globocan.iarc.fr

13. Altobelli E, Lattanzi A, Paduano R, Varassi G, di Orio F. Colorectal cancer prevention in Europe: burden of disease and status of screening programs. Prev Med (2014) 62:132-41. doi:10.1016/j.ypmed.2014.02.010

14. Hill MJ, Morson BC, Bussey HJ. Aetiology of adenoma-carcinoma sequence in large bowel. Lancet (1978) 1:245-7. doi:10.1016/S0140-6736(78)90487-7

15. Elmunzer BJ, Hayward RA, Schoenfeld PS, Saini SD, Deshpande A, Waljee AK. Effect of flexible sigmoidoscopy-based screening on incidence and mortality of colorectal cancer: a systematic review and meta-analysis of randomized controlled trials. PLoS Med (2012) 9:e1001352. doi:10.1371/journal.pmed.1001352

16. Brenner H, Chang-Claude J, Seiler CM, Rickert A, Hoff Meister M. Protection from colorectal cancer after colonoscopy: a population based, casecontrol study. Ann Intern Med (2011) 154:22-30. doi:10.7326/0003-4819-1541-201101040-00004

17. Nishihara R, Wu K, Lochhead P, Morikawa T, Liao X, Qian ZR, et al. Long-term colorectal-cancer incidence and mortality after lower endoscopy. N Engl J Med (2013) 369:1095-105. doi:10.1056/NEJMoa1301969

18. Ventura L, Mantellini P, Grazzini G, Castiglione G, Buzzoni C, Rubeca T, et al. The impact of immunochemical faecal occult blood testing on colorectal cancer incidence. Dig Liver Dis (2014) 46:82-6. doi:10.1016/j.dld.2013.07.017

19. Holme Ø, Bretthauer M, Fretheim A, Odgaard-Jensen J, Hoff G. Flexible sigmoidoscopy versus faecal occult blood testing for colorectal cancer screening in asymptomatic individuals. Cochrane Database Syst Rev (2013) 9:CD009259. doi:10.1002/14651858.CD009259.pub2

20. Whitlock EP, Lin JS, Liles E, Beil TL, Fu R. Screening for colorectal cancer: a targeted, updated systematic review for the U.S. Preventive Services Task Force. Ann Intern Med (2008) 149:638-58. doi:10.7326/0003-4819-149-9200811040-00245

21. Segnan N, Patnick J, Karsa LV editors. European Guidelines for Quality Assurance in Colorectal Cancer Screening and Diagnosis. Luxembourg: Office for Official Publications of the European Communities (2010).

22. Federici A, Giorgi Rossi P, Borgia P, Bartolozzi F, Farchi S, Gausticchi G. The immunochemical faecal occult blood test leads to higher compliance than the guaiac for colorectal cancer screening programmes: a cluster randomized controlled trial. J Med Screen (2005) 12:83-8. doi:10.1258/0969141053908357

23. Kaminski MF, Bretthauer M, Zauber AG, Kuipers EJ, Adami HO, van Ballegooijen M, et al. The NordICC Study: rationale and design of a randomized trial on colonoscopy screening for colorectal cancer. Endoscopy (2012) 44:695-702. doi:10.1055/s-0032-1306895

24. Quintero E, Castells A, Bujanda L, Cubiella J, Salas D, Lanas Á, et al. Colonoscopy versus fecal immunochemical testing in colorectal-cancer screening. N Engl J Med (2012) 366:697-706. doi:10.1056/NEJMoal108895

25. Robertson DJ. Digestive Diseases Week 2011: VA Cooperative Study \#577. Colonoscopy vs. Fecal Immunological Test in Reducing Mortality from Colorectal Cancer (CONFIRM). Available from: http://clinicaltrials.gov/ct2/show/ NCT01239082

26. Pox CP. Controversies in colorectal cancer screening. Digestion (2014) 89:274-81. doi:10.1159/000363287

27. Lansdorp-Vogelaar I, Knudsen AB, Brenner H. Cost-effectiveness of colorectal cancer screening. Epidemiol Rev (2011) 33:88-100. doi:10.1093/epirev/ $\mathrm{mxr} 004$

28. Cruzado J, Sánchez FI, Abellán JM, Pérez-Riquelme F, Carballo F. Economic evaluation of colorectal cancer (CRC) screening. Best Pract Res Clin Gastroenterol (2013) 27:867-80. doi:10.1016/j.bpg.2013.09.004

29. Young PE, Womeldorph CM. Colonoscopy for colorectal cancer screening. J Cancer (2013) 4:217-26. doi:10.7150/jca.5829

30. Hardcastle JD, Chamberlain JO, Robinson MH, Moss SM, Amar SS, Balfour TW, et al. Randomised controlled trial of faecal-occult-blood screening for colorectal cancer. Lancet (1996) 348:1472-7. doi:10.1016/S0140-6736(96)03386-7

31. Kronborg O, Fenger C, Olsen J, Jørgensen OD, Søndergaard O. Randomised study of screening for colorectal cancer with faecal-occult-blood test. Lancet (1996) 348:1467-71. doi:10.1016/S0140-6736(96)03430-7

32. Mandel JS, Church TR, Ederer F, Bond JH. Colorectal cancer mortality: effectiveness of biennial screening for fecal occult blood. J Natl Cancer Inst (1999) 91:434-7. doi:10.1093/jnci/91.5.434

33. Lindholm E, Brevinge H, Haglind E. Survival benefit in a randomized clinical trial of faecal occult blood screening for colorectal cancer. Br J Surg (2008) 95:1029-36. doi:10.1002/bjs.6136
34. Hewitson P, Glasziou P, Irwig L, Towler B, Watson E. Screening for colorectal cancer using the faecal occult blood test, Hemoccult. Cochrane Database Syst $\operatorname{Rev}(2007)$ 1:CD001216. doi:10.1002/14651858

35. Sinatra MA, St John DJ, Young GP. Interference of plant peroxidases with guaiac-based fecal occult blood tests is avoidable. Clin Chem (1999) 45:123-6.

36. Pignone M, Campbell MK, Carr C, Phillips C. Meta-analysis of dietary restriction during fecal occult blood testing. Eff Clin Pract (2001) 4:150-6.

37. O'Malley AS, Beaton E, Yabroff K, Abramson R, Mandelblatt J. Patient and provider barriers to colorectal cancer screening in the primary care safety-net. Prev Med (2004) 39:56-63. doi:10.1016/j.ypmed.2004.02.022

38. Konrad G. Dietary interventions for fecal occult blood test screening: systematic review of the literature. Can Fam Physician (2010) 56:229-38.

39. Duffy MJ, van Rossum LG, van Turenhout ST, Malminiemi O, Sturgeon C, Lamerz R, et al. Use of faecal markers in screening for colorectal neoplasia: a European group on tumor markers position paper. Int J Cancer (2011) 128:3-11. doi:10.1002/ijc.25654

40. Young GP. Population-based screening for colorectal cancer: Australian research and implementation. J Gastroenterol Hepatol (2009) 24(Suppl 3):S33-42. doi:10.1111/j.1440-1746.2009.06069.x

41. Mandel JS, Bond JH, Church TR, Snover DC, Bradley GM, Schuman LM, et al. Reducing mortality from colorectal cancer by screening for fecal occult blood. Minnesota Colon Cancer Control Study. N Engl J Med (1993) 328:1365-71. doi:10.1056/NEJM199305133281901

42. Levin B, Lieberman DA, McFarland B, Andrews KS, Brooks D, Bond J, et al. American Cancer Society Colorectal Cancer Advisory Group; US MultiSociety Task Force; American College of Radiology Colon Cancer Committee. Screening and surveillance for the early detection of colorectal cancer and adenomatous polyps, 2008: a joint guideline from the American Cancer Society, the US Multi-Society Task Force on Colorectal Cancer, and the American College of Radiology. Gastroenterology (2008) 134:1570-95. doi:10.1053/j.gastro.2008.02.002

43. Young GP, Sinatra MA, St John DJ. Influence of delay in stool sampling on fecal occult blood test sensitivity. Clin Chem (1996) 42:1107-8.

44. Zorzi M, Fedeli U, Schievano E, Bovo E, Guzzinati S, Baracco S, et al. Impact on colorectal cancer mortality of screening programmes based on the faecal immunochemical test. Gut (2014). doi:10.1136/gutjnl-2014-307508

45. Smith A, Young GP, Cole SR, Bampton P. Comparison of a brush-sampling fecal immunochemical test for hemoglobin with a sensitive guaiac-based fecal occult blood test in detection of colorectal neoplasia. Cancer (2006) 107:2152-9. doi: $10.1002 /$ cncr.22230

46. Levi Z, Hazazi R, Rozen P, Vilkin A, Waked A, Niv Y. A quantitative immunochemical faecal occult blood test is more efficient for detecting significant colorectal neoplasia than a sensitive guaiac test. Aliment Pharmacol Ther (2006) 23:1359-64. doi:10.1111/j.1365-2036.2006.02898.x

47. Guittet L, Bouvier V, Mariotte N, Vallee JP, Arsène D, Boutreux S, et al. Comparison of a guaiac based and an immunochemical faecal occult blood test in screening for colorectal cancer in a general average risk population. Gut (2007) 56:210-4. doi:10.1136/gut.2006.101428

48. Dancourt V, Lejeune C, Lepage C, Gailliard MC, Meny B, Faivre J. Immunochemical faecal occult blood tests are superior to guaiac-based tests for the detection of colorectal neoplasms. Eur J Cancer (2008) 44:2254-8. doi:10.1016/ j.ejca.2008.06.041

49. Guittet L, Bouvier V, Mariotte N, Vallee JP, Levillain R, Tichet J, et al. Comparison of a guaiac and an immunochemical faecal occult blood test for the detection of colonic lesions according to lesion type and location. Br J Cancer (2009) 100:1230-5. doi:10.1038/sj.bjc.6604996

50. van Rossum LG, van Rijn AF, Laheij RJ, van Oijen MG, Fockens P, van Krieken $\mathrm{HH}$, et al. Random comparison of guaiac and immunochemical fecal occult blood tests for colorectal cancer in a screening population. Gastroenterology (2008) 135:82-90. doi:10.1053/j.gastro.2008.03.040

51. Rozen P, Levi Z, Hazazi R, Waked A, Vilkin A, Maoz E, et al. Quantitative colonoscopic evaluation of relative efficiencies of an immunochemical faecal occult blood test and a sensitive guaiac test for detecting significant colorectal neoplasms. Aliment Pharmacol Ther (2009) 29:450-7. doi:10.1111/j.13652036.2008.03898.x

52. Hol L, van Leerdam ME, van Ballegooijen M, van Vuuren AJ, van Dekken H, Reijerink JC, et al. Screening for colorectal cancer: randomised trial comparing guaiac-based and immunochemical faecal occult blood testing and flexible sigmoidoscopy. Gut (2010) 59:62-8. doi:10.1136/gut.2009.177089 
53. Park DI, Ryu S, Kim YH, Lee SH, Lee CK, Eun CS, et al. Comparison of guaiacbased and quantitative immunochemical fecal occult blood testing in a population at average risk undergoing colorectal cancer screening. Am J Gastroenterol (2010) 105:2017-25. doi:10.1038/ajg.2010.179

54. Levi Z, Birkenfeld S, Vilkin A, Bar-Chana M, Lifshitz I, Chared M, et al. A higher detection rate for colorectal cancer and advanced adenomatous polyp for screening with immunochemical fecal occult blood test than guaiac fecal occult blood test, despite lower compliance rate. A prospective, controlled, feasibility study. Int J Cancer (2011) 128:2415-24. doi:10.1002/ijc.25574

55. Rozen P, Comaneshter D, Levi Z, Hazazi R, Vilkin A, Maoz E, et al. Cumulative evaluation of a quantitative immunochemical fecal occult blood test to determine its optimal clinical use. Cancer (2010) 116:2115-25. doi:10.1002/cncr. 25012

56. Hundt S, Haug U, Brenner H. Comparative evaluation of immunochemical fecal occult blood tests for colorectal adenoma detection. Ann Intern Med (2009) 150:162-9. doi:10.7326/0003-4819-150-3-200902030-00005

57. Nakama H, Zhang B, Fattah AS. A cost-effective analysis of the optimum number of stool specimens collected for immunochemical occult blood screening for colorectal cancer. Eur J Cancer (2000) 36:647-50. doi:10.1016/S09598049(00)00020-4

58. Castiglione G, Grazzini G, Miccinesi G, Rubeca T, Sani C, Turco P, et al. Basic variables at different positivity thresholds of a quantitative immunochemical test for faecal occult blood. J Med Screen (2002) 9:99-103. doi:10. 1136/jms.9.3.99

59. Bampton PA, Sandford JJ, Cole SR, Smith A, Morcom J, Cadd B, et al. Interval faecal occult blood testing in a colonoscopy based screening programme detects additional pathology. Gut (2005) 54:803-6. doi:10.1136/gut.2004.043786

60. Morikawa T, Kato J, Yamaji Y, Wada R, Mitsushima T, Sakaguchi K, et al. Sensitivity of immunochemical fecal occult blood test to small colorectal adenomas. Am J Gastroenterol (2007) 102:2259-64. doi:10.1111/j.1572-0241.2007.01404.x

61. Lee JK, Liles EG, Bent S, Levin TR, Corley DA. Accuracy of fecal immunochemical tests for colorectal cancer. Systematic review and meta-analysis. Ann Intern Med (2014) 160:171-81. doi:10.7326/M13-1484

62. Cole SR, Young GP, Esterman A, Cadd B, Morcom J. A randomised trial of the impact of new faecal haemoglobin test technologies on population participation in screening for colorectal cancer. J Med Screen (2003) 10:117-22. doi:10.1258/096914103769011003

63. Levi Z, Rozen P, Hazazi R, Vilkin A, Waked A, Maoz E, et al. A quantitative immunochemical fecal occult blood test for colorectal neoplasia. Ann Intern Med (2007) 146:244-55. doi:10.7326/0003-4819-146-4-200702200-00003

64. Grazzini G, Ventura L, Zappa M, Ciatto S, Confortini M, Rapi S, et al. Influence of seasonal variations in ambient temperatures on performance of immunochemical faecal occult blood test for colorectal cancer screening: observational study from the Florence district. Gut (2010) 59:1511-5. doi:10.1136/gut.2009.200873

65. Hol L, Wilschut JA, van Ballegooijen M, van Vuuren AJ, van der Valk H, Reijerink JC, et al. Screening for colorectal cancer: random comparison of guaiac and immunochemical faecal occult blood testing at different cut-off levels. $\mathrm{Br}$ J Cancer (2009) 100:1103-10. doi:10.1038/sj.bjc.6604961

66. Fraser CG, Matthew CM, Mowat NA, Wilson JA, Carey FA, Steele RJ. Immunochemical testing of individuals positive for guaiac faecal occult blood test in a screening programme for colorectal cancer: an observational study. Lancet Oncol (2006) 7:127-31. doi:10.1016/S1470-2045(05)70473-3

67. Flitcroft KL, Irwig LM, Carter SM, Salkeld GP, Gillespie JA. Colorectal cancer screening: why immunochemical fecal occult blood tests may be the best option. BMC Gastroenterol (2012) 12:183. doi:10.1186/1471-230X-12-183

68. Guittet L, Bouvier V, Guillaume E, Levillain R, Ruiz A, Lantieri O, et al. Colorectal cancer screening: why immunochemical faecal occult blood test performs as well with either one or two samples. Dig Liver Dis (2012) 44:694-9. doi:10.1016/j.dld.2012.03.005

69. Atkin WS, Edwards R, Kralj-Hans I, Wooldrage K, Hart AR, Northover JM, et al. Once-only flexible sigmoidoscopy screening in prevention of colorectal cancer: a multicentre randomised controlled trial. Lancet (2010) 375:1624-33. doi:10.1016/S0140-6736(10)60551-X

70. Segnan N, Armaroli P, Bonelli L, Risio M, Sciallero S, Zappa M, et al. Once-only sigmoidoscopy in colorectal cancer screening: follow-up findings of the Italian Randomized Controlled Trial-SCORE. J Natl Cancer Inst (2011) 103:1310-22. doi:10.1093/jnci/djr284
71. Schoen RE, Pinsky PF, Weissfeld JL, Yokochi LA, Church T, Laiyemo AO, et al. Colorectal-cancer incidence and mortality with screening flexible sigmoidoscopy. N Engl J Med (2012) 366:2345-57. doi:10.1056/NEJMoa1114635

72. Holme $\varnothing$, Løberg M, Kalager M, Bretthauer M, Hernán MA, Aas E, et al. Effect of flexible sigmoidoscopy screening on colorectal cancer incidence and mortality: a randomized clinical trial. JAMA (2014) 312(6):606-15. doi:10.1001/jama.2014.8266

73. Lieberman DA, Weiss DG. One-time screening for colorectal cancer with combined fecal occult-blood testing and examination of the distal colon. $N$ Engl J Med (2001) 345:555-60. doi:10.1056/NEJMoa010328

74. Berry DP, Clarke P, Hardcastle JD, Vellacott KD. Randomized trial of the addition of flexible sigmoidoscopy to faecal occult blood testing for colorectal neoplasia population screening. Br J Surg (1997) 84:1274-6. doi:10.1002/bjs. 1800840922

75. Rasmussen M, Kronborg O, Fenger C, Jørgensen OD. Possible advantages and drawbacks of adding flexible sigmoidoscopy to hemoccult-II in screening for colorectal cancer. A randomized study. Scand J Gastroenterol (1999) 34:73-8. doi: 10.1080/00365529950172862

76. Levin TR, Conell C, Shapiro JA, Chazan SG, Nadel MR, Selby JV. Complications of screening flexible sigmoidoscopy. Gastroenterology (2002) 123:1786-92. doi:10.1053/gast.2002.37064

77. Rex DK, Rahmani EY, Haseman JH, Lemmel GT, Kaster S, Buckley JS. Relative sensitivity of colonoscopy and barium enema for detection of colorectal cancer in clinical practice. Gastroenterology (1997) 112:17-23. doi:10.1016/S00165085(97)70213-0

78. Avidan B, Sonnenberg A, Schnell TG, Leya J, Metz A, Sontag SJ. New occurrence and recurrence of neoplasms within 5 years of a screening colonoscopy. Am J Gastroenterol (2002) 97:1524-9. doi:10.1111/j.1572-0241.2002.05801.x

79. Pickhardt PJ, Choi JR, Hwang I, Butler JA, Puckett ML, Hildebrandt HA, et al. Computed tomographic virtual colonoscopy to screen for colorectal neoplasia in asymptomatic adults. N Engl J Med (2003) 349:2191-200. doi:10.1056/NEJMoa031618

80. Hosokawa O, Shirasaki S, Kaizaki Y, Hayashi H, Douden K, Hattori M. Invasive colorectal cancer detected up to 3 years after a colonoscopy negative for cancer. Endoscopy (2003) 35:506-10. doi:10.1055/s-2003-39665

81. Farrar WD, Sawhney MS, Nelson DB, Lederle FA, Bond JH. Colorectal cancers found after a complete colonoscopy. Clin Gastroenterol Hepatol (2006) 4:1259-64. doi:10.1016/j.cgh.2006.07.012

82. Bressler B, Paszat LF, Chen Z, Rothwell DM, Vinden C, Rabeneck L. Rates of new or missed colorectal cancers after colonoscopy and their risk factors: a population-based analysis. Gastroenterology (2007) 132:96-102. doi:10.1053/j. gastro.2006.10.027

83. U.S. Preventive Services Task Force. Screening for colorectal cancer: U.S. Preventive Services Task Force recommendation statement. Ann Intern Med (2008) 149:627-37. doi:10.7326/0003-4819-149-9-200811040-00243

84. Winawer SJ, Zauber AG, Ho MN, O’Brien MJ, Gottlieb LS, Sternberg SS, et al. Prevention of colorectal cancer by colonoscopic polypectomy. The National Polyp Study Workgroup. N Engl J Med (1993) 329:1977-81. doi:10.1056/ NEJM199312303292701

85. Citarda F, Tomaselli G, Capocaccia R, Barcherini S, Crespi M, Italian Multicentre Study Group. Efficacy in standard clinical practice of colonoscopic polypectomy in reducing colorectal cancer incidence. Gut (2001) 48:812-5. doi:10.1136/gut.48.6.812

86. Baxter NN, Goldwasser MA, Paszat LF, Saskin R, Urbach DR, Rabeneck L. Association of colonoscopy and death from colorectal cancer. Ann Intern Med (2009) 150:1-8. doi:10.7326/0003-4819-150-1-200901060-00306

87. Zauber AG, Winawer SJ, O’Brien MJ, Lansdorp-Vogelaar I, van Ballegooijen $\mathrm{M}$, Hankey BF, et al. Colonoscopic polypectomy and longterm prevention of colorectal-cancer deaths. N Engl J Med (2012) 366:687-96. doi:10.1056/ NEJMoa1100370

88. Kaminski MF, Regula J, Kraszewska E, Polkowski M, Wojciechowska U, Didkowska J, et al. Quality indicators for colonoscopy and the risk of interval cancer. N Engl J Med (2010) 362:1795-803. doi:10.1056/ NEJMoa0907667

89. Brenner H, Hoffmeister M, Arndt V, Stegmaier C, Altenhofen L, Haug U. Protection from right- and left-sided colorectal neoplasms after colonoscopy: population-based study. J Natl Cancer Inst (2010) 102:89-95. doi:10.1093/jnci/ djp436 
90. Singh H, Nugent Z, Mahmud SM, Demers AA, Bernstein CN. Predictors of colorectal cancer after negative colonoscopy: a population-based study. Am J Gastroenterol (2010) 105:663-73. doi:10.1038/ajg.2009.650

91. Rex DK, Bond JH, Winawer S, Levin TR, Burt RW, Johnson DA, et al. Quality in the technical performance of colonoscopy and the continuous quality improvement process for colonoscopy: recommendations of the US MultiSociety Task Force on colorectal cancer. Am J Gastroenterol (2002) 97:1296-308. doi:10.1111/j.1572-0241.2002.05812.x

92. Shapiro JA, Klabunde CN, Thompson TD, Nadel MR, Seeff LC, White A. Patterns of colorectal cancer test use, including CT colonography, in the 2010 National Health Interview Survey. Cancer Epidemiol Biomarkers Prev (2012) 21:895-904. doi:10.1158/1055-9965.EPI-12-0192

93. Pox C, Schmiegel W, Classen M. Current status of screening colonoscopy in Europe and in the United States. Endoscopy (2007) 39:168-73. doi:10.1055/s2007-966182

94. Center MM, Jemal A, Smith RA, Ward E. Worldwide variations in colorectal cancer. CA Cancer J Clin (2009) 59:366-78. doi:10.3322/caac.20038

95. Binefa G, Rodríguez-Moranta F, Teule A, Medina-Hayas M. Colorectal cancer: from prevention to personalized medicine. World J Gastroenterol (2014) 20:6786-808. doi:10.3748/wig.v20.i22.6786

96. Smith RA, Manassaram-Baptiste D, Brooks D, Cokkinides V, Doroshenk M, Saslow D, et al. Cancer screening in the United States, 2014: a review of current American Cancer Society guidelines and current issues in cancer screening. $C A$ Cancer J Clin (2014) 64:30-51. doi:10.3322/caac.21212

97. Yang DX, Gross CP, Soulos PR, Yu JB. Estimating the magnitude of colorectal cancers prevented during the era of screening: 1976 to 2009. Cancer (2014) 120:2893-901. doi:10.1002/cncr.28794

98. Zapka J, Klabunde CN, Taplin S, Yuan G, Ransohoff D, Kobrin S. Screening colonoscopy in the US: attitudes and practices of primary care physicians. J Gen Intern Med (2012) 27:1150-8. doi:10.1007/s11606-012-2051-3

99. Lee CS, Ronan L, O’Morain C, McNamara D. Screening for colorectal cancer: what fits best? Expert Rev Gastroenterol Hepatol (2012) 6:301-12. doi:10.1586/ egh. 12.12

100. Allison JE, Fraser CG, Halloran SP, Young GP. Population screening for colorectal cancer means getting FIT: the past, present, and future of colorectal cancer screening using the fecal immunochemical test for hemoglobin (FIT). Gut Liver (2014) 8:117-30. doi:10.5009/gnl.2014.8.2.117

101. Hassan C, Giorgi Rossi P, Camilloni L, Rex DK, Jimenez-Cendales B, Ferroni E, et al. Meta-analysis: adherence to colorectal cancer screening and the detection rate for advanced neoplasia, according to the type of screening test. Aliment Pharmacol Ther (2012) 36:929-40. doi:10.1111/apt.12071

102. Brenner H, Chang-Claude J, Jansen L, Knebel P, Stock C, Hoffmeister M. Reduced risk of colorectal cancer up to 10 years after screening, surveillance, or diagnostic colonoscopy. Gastroenterology (2014) 146:709-17. doi:10.1053/j. gastro.2013.09.001

103. Segnan N, Senore C, Andreoni B, Azzoni A, Bisanti L, Cardelli A, et al. Comparing attendance and detection rate of colonoscopy with sigmoidoscopy and FIT for colorectal cancer screening. Gastroenterology (2007) 132:2304-12. doi:10.1053/j.gastro.2007.03.030

104. Salas D, Vanaclocha M, Ibáñez J, Molina-Barceló A, Hernández V, Cubiella J, et al. Participation and detection rates by age and sex for colonoscopy versus fecal immunochemical testing in colorectal cancer screening. Cancer Causes Control (2014) 25:985-97. doi:10.1007/s10552-014-0398-y

105. Massat NJ, Moss SM, Halloran SP, Duffy SW. Screening and primary prevention of colorectal cancer: a review of sex-specific and site-specific differences. J Med Screen (2013) 20:125-48. doi:10.1177/0969141313501292

106. Moss SM, Campbell C, Melia J, Coleman D, Smith S, Parker R, et al. Performance measures in three rounds of the English bowel cancer screening pilot. Gut (2012) 61:101-7. doi:10.1136/gut.2010.236430

107. Zorzi M, Fedato C, Grazzini G, Sassoli De’ Bianchi P, Naldoni C, Pendenza $\mathrm{M}$, et al. Screening for colorectal cancer in Italy, 2010 survey. Epidemiol Prev (2012) 36(S1):55-77.

108. Jepson R, Clegg A, Forbes C, Lewis R, Sowden A, Kleijnen J. The determinants of screening uptake and interventions for increasing uptake: a systematic review. Health Technol Assess (2000) 4(i-vii):1-133. doi:10.3310/hta4140

109. Camilloni L, Ferroni E, Cendales BJ, Pezzarossi A, Furnari G, Borgia P, et al. Methods to increase participation in organised screening programs: a systematic review. BMC Public Health (2013) 13:464. doi:10.1186/1471-245813-464
110. Gupta S, Sussman DA, Doubeni CA, Anderson DS, Day L, Deshpande AR, et al. Challenges and possible solutions to colorectal cancer screening for the underserved. J Natl Cancer Inst (2014) 106:dju032. doi:10.1093/jnci/dju032

111. Haug U, Rösch T, Hoffmeister M, Katalinic A, Brenner H, Becker N. Implementing an Organised Colorectal Cancer Screening Programme in Germany: Opportunities and Challenges. Gesundheitswesen (2014). doi:10.1055/s-0034-1377027

112. Boguradzka A, Wiszniewski M, Kaminski MF, Kraszewska E, Mazurczak-Pluta $T$, Rzewuska $\mathrm{D}$, et al. The effect of primary care physician counseling on participation rate and use of sedation in colonoscopy-based colorectal cancer screening program - a randomized controlled study. Scand J Gastroenterol (2014) 49:878-84. doi:10.3109/00365521.2014.913191

113. Senore C, Ederle A, Benazzato L, Arrigoni A, Silvani M, Fantin A, et al. Offering people a choice for colorectal cancer screening. Gut (2013) 62:735-40. doi:10.1136/gutjnl-2011-301013

114. Hol L, Kuipers EJ, van Ballegooijen M, van Vuuren AJ, Reijerink JC, Habbema DJ, et al. Uptake of faecal immunochemical test screening among nonparticipants in a flexible sigmoidoscopy screening programme. Int J Cancer (2012) 130:2096-102. doi:10.1002/ijc.26260

115. Fesler A, Jiang J, Zhai H, Ju J. Circulating microRNA testing for the early diagnosis and follow-up of colorectal cancer patients. Mol Diagn Ther (2014) 18:303-8. doi:10.1007/s40291-014-0089-0

116. Dinh T, Ladabaum U, Alperin P, Caldwell C, Smith R, Levin TR. Health benefits and cost-effectiveness of a hybrid screening strategy for colorectal cancer. Clin Gastroenterol Hepatol (2013) 11:1158-66. doi:10.1016/j.cgh.2013.03.013

117. Gralnek IM, Siersema PD, Halpern Z, Segol O, Melhem A, Suissa A, et al. Standard forward-viewing colonoscopy versus full-spectrum endoscopy: an international, multicentre, randomised, tandem colonoscopy trial. Lancet Oncol (2014) 15:353-60. doi:10.1016/S1470-2045(14)70020-8

118. Ahlquist DA, Sargent DJ, Loprinzi CL, Levin TR, Rex DK, Ahnen DJ, et al. Stool DNA and occult blood testing for screen detection of colorectal neoplasia. Ann Intern Med (2008) 149:441-50. doi:10.7326/0003-4819-149-7200810070-00004

119. Imperiale TF, Ransohoff DF, Itzkowitz SH, Turnbull BA, Ross ME. Fecal DNA versus fecal occult blood for colorectal cancer screening in an average-risk population. N Engl J Med (2004) 351:2704-14. doi:10.1056/NEJMoa033403

120. Imperiale TF, Ransohoff DF, Itzkowitz SH, Levin TR, Lavin P, Lidgard GP, et al. Multitarget stool DNA testing for colorectal-cancer screening. $N$ Engl J Med (2014) 370:1287-97. doi:10.1056/NEJMoa1311194

121. Liotta LA, Ferrari M, Petricoin E. Written in blood. Nature (2003) 425:905. doi:10.1038/425905a

122. Halligan S, Wooldrage K, Dadswell E, Kralj-Hans I, von Wagner C, Edwards R, et al. Computed tomographic colonography versus barium enema for diagnosis of colorectal cancer or large polyps in symptomatic patients (SIGGAR): a multicentre randomised trial. Lancet (2013) 381:1185-93. doi:10.1016/S01406736(12)62124-2

123. von Wagner C, Smith S, Halligan S, Ghanouni A, Power E, Lilford RJ, et al. Patient acceptability of CT colonography compared with double contrast barium enema: results from a multicentre randomised controlled trial of symptomatic patients. Eur Radiol (2011) 21:2046-55. doi:10.1007/s00330-011-2154-y

124. Pickhardt PJ, Hassan C, Halligan S, Marmo R. Colorectal cancer: CT colonography and colonoscopy for detection-systematic review and meta-analysis. Radiology (2011) 259:393-405. doi:10.1148/radiol.11101887

125. Sosna J, Morrin MM, Kruskal JB, Lavin PT, Rosen MP, Raptopoulos V. CT colonography of colorectal polyps: a meta-analysis. AJR Am J Roentgenol (2003) 181:1593-8. doi:10.2214/ajr.181.6.1811593

126. Mulhall BP, Veerappan GR, Jackson JL. Meta-analysis: computed tomographic colonography. Ann Intern Med (2005) 142:635-50. doi:10.7326/0003-4819142-8-200504190-00013

127. Rosman AS, Korsten MA. Meta-analysis comparing CT colonography, air contrast barium enema, and colonoscopy. Am J Med (2007) 120:203-10. doi:10.1016/j.amjmed.2006.05.061

128. Halligan S, Altman DG, Taylor SA, Mallett S, Deeks JJ, Bartram CI, et al. CT colonography in the detection of colorectal polyps and cancer: systematic review, meta-analysis, and proposed minimum data set for study level reporting. Radiology (2005) 237:893-904. doi:10.1148/radiol.2373050176

129. Chaparro M, Gisbert JP, del Campo L, Cantero J, Maté J. Accuracy of computed tomographic colonography for the detection of polyps and colorectal tumors: a systematic review and meta-analysis. Digestion (2009) 80:1-17. doi:10.1159/000215387 
130. Pickhardt PJ. Incidence of colonic perforation at CT colonography: review of existing data and implications for screening of asymptomatic adults. Radiology (2006) 239:313-6. doi:10.1148/radiol.2392052002

131. Mani A, Napel S, Paik DS, Jeffrey RB Jr., Yee J, Olcott EW, et al. Computed tomography colonography: feasibility of computer-aided polyp detection in a first reader paradigm. J Comput Assist Tomogr (2004) 28:318-32. doi:10.1097/00004728-200405000-00003

132. Iussich G, Correale L, Senore C, Hassan C, Segnan N, Campanella D, et al. Computer-aided detection for computed tomographic colonography screening. Invest Radiol (2014) 49:173-82. doi:10.1097/RLI.0000000000000009

133. Stoop EM, de Haan MC, de Wijkerslooth TR, Bossuyt PM, van Ballegooijen $\mathrm{M}$, Nio CY, et al. Participation and yield of colonoscopy versus non-cathartic CT colonography in population-based screening for colorectal cancer: a randomised controlled trial. Lancet Oncol (2012) 13:55-64. doi:10.1016/S14702045(11)70283-2

134. Pickhardt PJ, Hanson ME, Vanness DJ, Lo JY, Kim DH, Taylor AJ, et al. Unsuspected extracolonic findings at screening CT colonography: clinical and economic impact. Radiology (2008) 249:151-9. doi:10.1148/radiol.2491072148

135. Sali L, Grazzini G, Carozzi F, Castiglione G, Falchini M, Mallardi B, et al. Screening for colorectal cancer with FOBT, virtual colonoscopy and optical colonoscopy: study protocol for a randomized controlled trial in the Florence district (SAVE study). Trials (2013) 14:74. doi:10.1186/1745-6215-14-74

136. Regge D, Iussich G, Senore C, Correale L, Hassan C, Bert A, et al. Population screening for colorectal cancer by flexible sigmoidoscopy or CT colonography: study protocol for a multicenter randomized trial. Trials (2014) 15:97. doi:10.1186/1745-6215-15-97

137. Sali L, Falchini M, Bonanomi AG, Castiglione G, Ciatto S, Mantellini P, et al. CT colonography after incomplete colonoscopy in subjects with positive faecal occult blood test. World J Gastroenterol (2008) 14:4499-504. doi:10.3748/wjg.14.4499

138. Van Gossum A, Munoz-Navas M, Fernandez-Urien I, Carretero C, Gay G, Delvaux $\mathrm{M}$, et al. Capsule endoscopy versus colonoscopy for the detection of polyps and cancer. N Engl J Med (2009) 361:264-70. doi:10.1056/NEJMoa0806347
139. Riccioni ME, Urgesi R, Cianci R, Bizzotto A, Spada C, Costamagna G. Colon capsule endoscopy: advantages, limitations and expectations. Which novelties? World J Gastrointest Endosc (2012) 4:99-107. doi:10.4253/ wjge.v4.i4.99

140. Eliakim R, Yassin K, NivY, Lachter J, Gal E, Sapoznikov B, et al. Prospective multicenter performance evaluation of the second-generation colon capsule compared with colonoscopy. Endoscopy (2009) 41:1026-31. doi:10.1055/s-00291215360

141. Spada C, Hassan C, Munoz-Navas M, Neuhaus H, Deviere J, Fockens P, et al. Second-generation colon capsule endoscopy compared with colonoscopy. Gastrointest Endosc (2011) 74:581-9. doi:10.1016/j.gie.2011.03.1125

142. Singhal S, Nigar S, Paleti V, Lane D, Duddempudi S. Bowel preparation regimens for colon capsule endoscopy: a review. Therap Adv Gastroenterol (2014) 7:115-22. doi:10.1177/1756283X13504730

Conflict of Interest Statement: The authors declare that the research was conducted in the absence of any commercial or financial relationships that could be construed as a potential conflict of interest.

Received: 28 August 2014; paper pending published: 14 September 2014; accepted: 10 October 2014; published online: 27 October 2014

Citation: Stracci F, Zorzi M and Grazzini G (2014) Colorectal cancer screening: tests, strategies, and perspectives. Front. Public Health 2:210. doi: 10.3389/fpubh.2014.00210 This article was submitted to Epidemiology, a section of the journal Frontiers in Public Health.

Copyright (c) 2014 Stracci, Zorzi and Grazzini. This is an open-access article distributed under the terms of the Creative Commons Attribution License (CC BY). The use, distribution or reproduction in other forums is permitted, provided the original author(s) or licensor are credited and that the original publication in this journal is cited, in accordance with accepted academic practice. No use, distribution or reproduction is permitted which does not comply with these terms. 